\title{
Nurses' Knowledge toward Traumatic Head Injury During Golden Hour
}

\author{
Sabah Abdullah Jaafar², Raja Ibrahim Abed ${ }^{2}$

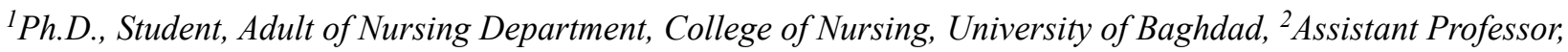 \\ Fundamental of Nursing Department, College of Nursing, University of Baghdad
}

\begin{abstract}
Background: Nurses have a central role in management critical ill patients, not only to save their life but to improve their outcomes. Also, there is no safe practice unless the nurses had enough knowledge.

Objectives: The objective of this study was to assess nurses' knowledge toward traumatic head injury during golden hour neurosurgical hospital, and to find out relationships between their demographics and total knowledge.

Method: A descriptive study using a purposive sample (non-probability) was used to survey 25 nurses who met the sampling criteria in one main neurosurgical hospital in Baghdad city to assess their knowledge toward traumatic head injury during golden hour.The official permission begin before study starting. The study starting from June $15^{\text {th }}$ July $14^{\text {th }} 2019$. Based on comprehensive literature, the tool of study constructed by the researcher and tested for validity and reliability.

Results: The majority of the study sample $64 \%$ were $(20-24)$ years old. Most of them were female (80\%), and $(52 \%)$ was married. Also, most study samples had high school nursing graduation (80\%). Regarding the workplace, most of the study sample(64\%) works in Neurosurgical ICU. Regarding years of experience, half of the study sample $(52 \%)$ had less than three years of experience in the current workplace and more than one-third (36\%)had total years of employment in nursing between 9 to 12 years. The majority of the study sample (52\%) has participated in training courses about traumatic head injury and (64\%) was the day shift of work. The total mean of the score of nurses' knowledge was fair (0.42).

Conclusion: Despite the total nurse's knowledge was fair $0.34-0.67$, the majority of them were junior, graduation from secondary school nursing, and had poor knowledge toward traumatic head injury during golden hour. On the other hand, $48 \%$ of nurses not participated in continuous education lectures about traumatic head injury. Regarding these results, researchers recommend encouraging nurses who had a diploma and bachelor in nursing to work in critical care units at neurosurgical hospital and update continuous education program lectures to cover all nurses to improve their knowledge about traumatic head injury.
\end{abstract}

Keywords: Traumatic head injury, Nurse, Knowledge, Golden Hour.

\section{Introduction}

In a critical care unit, where the patient takes the closely monitoring and advance health care by a

\author{
Corresponding Author: \\ Sabah Abdullah Jaafar \\ Ph.D., Student. Adult of Nursing Department, College \\ of Nursing, University of Baghdad \\ e-mail: sabah.abd@mu.edu.iq
}

multi-disciplinary team, nurse have a central role, in the identification of patient problems, the ability to solve problems, anticipating and preventing possible complications. Therefore, the development and enhancement of nurses knowledge are necessary to promote clinical judgment ${ }^{[1]}$. The enhancement of the nurses' knowledge and skill in the care of the patients with a traumatic head injury, is the most important way to promote their patients' outcomes. So, the enhancement includes, well-structured of evidence- 
based information and continuous practice in the hospital area ${ }^{[2]}$. Kinds of literature mentions, knowledge base and learning in nursing are long-life aspects and essential to maintaining not only their competencies also encouraged to improve their clinical practice. Indeed, the importance of lable nurses' knowledge level and the significance of educational components programs in the improvement of their knowledge ${ }^{[3,4]}$. Works of literature discussed the factors that can effects patients outcomes after traumatic brain injury, one of these factors is how the patients managed at injury moment and the definite care does not include only in the field of injury, may continue at a hospital ${ }^{[4,5]}$. In Iraq, the country that fought terrorism on behalf of the world, in the last two decades, the incidence of traumatic head injury increase to peak since the first gulf war. Traumatic head injury increase, related to many factors including, terrorism attacks, uses of not programmed weapon, and lack of road safety ${ }^{[6]}$. According to the Iraqi Medico-Legal study report, fatal head injuries have high percents among medico-legal deaths and $24 \%$ of cases death is delayed after different periods from the admission to the hospital ${ }^{[7]}$. Basrah, one of the largest cities in the south of Iraq, the mortality rate was significant in-hospital, even head injury was mild ${ }^{[6]}$. Despite much literature, well-known nurses $>$ knowledge in a critical care setting in Iraq, the little study focused on the management of traumatic head injury and there is no study to assess nurse >s knowledge toward traumatic head injury during the golden hour ${ }^{[8]}$.

\section{Material and Method}

Design: This is a descriptive study that was conducted to describe nurses' knowledge toward traumatic head injury during golden hour using a questionnaire that contains questions based on the best available information.

Ethical Approval: This study was approved by the Institutional Ethics Committee, and The IRB was obtained from the University of Baghdad and the Ministry of Health, Directorate of Al Rusafaa Health Administration in Baghdad city. The purpose of the study was explained to the nurses who work in the ICU and emergency unit in the neurosurgical hospital. The informed consent was reviewed and permitted by the Center of Staff Development and Scientific Research. Every participant had the right to withdraw and refuse participation from the study at any time without any penalties.
Study sample: A non-probability (purposive) sample technique was used to collect the data. The populations are nurses who work in ICU and emergency in Neurosurgical hospital. The target population that provided the sample data was a group of nurses who met the sampling criteria. The official permission begin before study starting. The study starting from June $15^{\text {th }}$ July $14^{\text {th }} 2019$.All male and female nurses with different educational levels who work in ICU and emergency were included in this study. Also, nurses who work in a day and night shifts were included in this study. The total sample size was 25 who agreed to participate in this study, the completed survey was included in the statistical analysis.

Instrument: Tools constructed by the researcher based on deep literature and standard textbooks in nursing. The validity of instruments obtained via 13 experts. The reliability of this tool shows was used testretest, Cronbach's alpha was 0.81 . This tool consists of 54 questions regarding traumatic head injury during golden hour in Neurosurgical critical care units. The total score for the tool measured based on the mean of the answers(poor knowledge, fair knowledge, and good knowledge). The code of correct answer was (1) for true and $(0)$ for a false answer.

Also, the first part of questionnaire included nurses' demographics: age, gender, level of education, years of experience in the ICU, total years of employment in nursing, a shift of work, and participation in continuous education lectures and seminars about traumatic head injury.

The second part of questionnaire contain five domains of knowledge include questions (anatomy and physiology of head and brain $=9$ questions, physiology of intracranial pressure,cerebral perfusion pressure and blood pressure $=16$ questions; primary and secondary survey domain $=10$ questions; Fluid supply $=7$ questions; and information about golden hour=12 questions).

Data Analysis: The statistics done by the Statistical Package for the Social Sciences (SPSS) version 24 software was used to perform the statistical analysis that included descriptive statistics (frequency, percentage, and mean of score) and inferential statistics (standard deviation and independent t-test and ANOVA).

Findings: In the Current study, twenty-five nurses have been studied in critical care units, were data analysis for the demographic characteristics' and association for 
all participants. Regarding descriptive data analysis were showed in table 1 , the mean of nurses' age was 25.1 and the standard deviation was 6.77 with a range of 20 to 39 years old. More than three-quarters of study samples were female gender accounts $80 \%$ and $20 \%$ were males. Concerning marital status, the majority of participants were married $52 \%$ and single accounts $48 \%$. Regarding educational status, $84 \%$ of study samples belonged to high school nursing graduation, $12 \%$ were medical institute graduation, and $4 \%$ college of nursing graduation. According to Neurosurgical hospital distribution, the majority of study participants $64 \%$ was work in the intensive care unit and $36 \%$ work in the emergency unit. More than two-third $88 \%$ of the study sample was day shift, night shift accounts $12 \%$. In regard to years of experience in the current place, $52 \%$ of the study sample was spent less than three years, $24 \%$ spent three to six years and $24 \%$ spent more than six-year. Also, total years of employment in nursing accounts $36 \%$ of study samples spent nine to twelve years as total years in nursing. Regarding participation in the training course, more than half the study subject $52 \%$ participated in training courses, and $48 \%$ have no participation in training courses.

Table 2 showed the level of assessment for study sample knowledge, $52 \%$ of study sample mean of the score was between 0.00 to 0.33 , accounts poor knowledge, 36\% was between $0.34-0.67$ accounts fair knowledge and $12 \%$ was between $0.68-1.00$ accounts good knowledge.

Table 3 showed nurses' age has significance association $(\mathrm{F}=6.850, \mathrm{p}=0.003)$ their knowledge. Regarding marital status, there is a significant association $(\mathrm{F}=6.600, \mathrm{p}=0.004)$ between nurses' educational status and their knowledge. The Nurses who reported for years' experience in the current place have no significance $(\mathrm{F}=0.827, \mathrm{p}=(0.642$ with their knowledge. Also, total years of employment in nursing have no significance association $(\mathrm{F}=0.561, \mathrm{p}=0.845)$ with their knowledge.

Finally, the result in table 4, tested by independent t-test shows, study sample gender have significance association( $\mathrm{t}=5.593, \mathrm{p}=0.000$ ) with their knowledge. However, there is no significant association $(\mathrm{t}=-0.482$, $\mathrm{p}=0.634$ ) between nurses' marital status and their knowledge toward traumatic head injury during the golden hour. Also, The result indicated there is no significant association $(\mathrm{t}=0.703, \mathrm{p}=0.439)$ between nurses working in emergency or intensive care unit and their level of knowledge. According to the work shift, there are no significant correlation $(\mathrm{t}=-2.016, \mathrm{p}=0.56)$ nurses who work in the day or night shift and their knowledge. Whatever, the analysis shows nosignificant differences $(t=0.181, p=0.858)$ between nurses who attended the training course and their level of knowledge.

Table (1): The table shows the distribution of the study sample regarding their demographics characteristics. $\mathbf{N}=(\mathbf{2 5})$

\begin{tabular}{|c|c|c|c|}
\hline \multicolumn{2}{|l|}{ Variables } & \multirow{2}{*}{$\begin{array}{c}\text { Frequency } \mathbf{F} \\
16\end{array}$} & \multirow{2}{*}{$\begin{array}{c}\text { Percent \% } \\
64.0\end{array}$} \\
\hline \multirow{4}{*}{$\begin{array}{l}\text { Age groups } \\
\mathrm{MS} \pm \mathrm{Sd}^{*} \\
25.1 \pm 6.77\end{array}$} & $(20-24)$ & & \\
\hline & $(25-29)$ & 4 & 16.0 \\
\hline & $(30-34)$ & 1 & 4.0 \\
\hline & $(35-39)$ & 4 & 16.0 \\
\hline \multirow{2}{*}{ Gender } & Male & 5 & 20.0 \\
\hline & Female & 20 & 80.0 \\
\hline \multirow{2}{*}{ Marital Status } & Single & 12 & 48.0 \\
\hline & Married & 13 & 52.0 \\
\hline \multirow{3}{*}{ Educational status } & Secondary school nursing & 21 & 84.0 \\
\hline & Diploma & 3 & 12.0 \\
\hline & Bachelor & 1 & 4.0 \\
\hline \multirow{3}{*}{$\begin{array}{l}\text { Years of Experience in the current } \\
\text { place }\end{array}$} & Less than 3 years & 13 & 52.0 \\
\hline & 3-6 years & 6 & 24.0 \\
\hline & More than 6 years & 6 & 24.0 \\
\hline
\end{tabular}




\begin{tabular}{|l|l|c|c|}
\hline \multicolumn{2}{|l|}{ Variables } & Frequency F & Percent \% \\
\hline \multirow{4}{*}{$\begin{array}{l}\text { Total years of employment in } \\
\text { nursing }\end{array}$} & $1-4))$ & 4 & 16.0 \\
\cline { 2 - 4 } & $5-8))$ & 4 & 16.0 \\
\cline { 2 - 4 } & $9-12))$ & 9 & 36.0 \\
\cline { 2 - 4 } & $13-16))$ & 4 & 16.0 \\
\cline { 2 - 4 } & $17-20))$ & 4 & 16.0 \\
\hline \multirow{3}{*}{ Work Field } & ER & 9 & 36.0 \\
\cline { 2 - 4 } & ICU & 16 & 64.0 \\
\hline \multirow{2}{*}{$\begin{array}{l}\text { Participation in continuous } \\
\text { education lecture }\end{array}$} & Yes & 13 & 52.0 \\
\cline { 2 - 4 } Shift & No & 12 & 48.0 \\
\hline
\end{tabular}

Table (2): Descriptive statistics Regarding levels of Assessment of Studied Sample knowledge N=(25):

\begin{tabular}{|c|c|c|c|c|c|c|}
\hline Variables & $\mathrm{N}=\mathbf{2 5}$ & Sum of Squares & df & Mean square & $\mathbf{F}$ & Sig.* \\
\hline \multirow{2}{*}{ Age Groups } & Between Groups & 0.524 & 3 & 0.175 & \multirow{2}{*}{22.332} & \multirow{2}{*}{0.000} \\
\hline & Within Groups & .1640 & 21 & .0080 & & \\
\hline \multirow{2}{*}{ Educational Status } & Between Groups & 0.013 & 2 & 0.006 & \multirow{2}{*}{0.204} & \multirow{2}{*}{0.817} \\
\hline & Between Groups & .6750 & 22 & .0310 & & \\
\hline \multirow{2}{*}{$\begin{array}{l}\text { Years of Experience in the current } \\
\text { workplace }\end{array}$} & Between Groups & 0.139 & 2 & 0.069 & \multirow{2}{*}{2.777} & \multirow{2}{*}{.0840} \\
\hline & Within Groups & .5490 & 22 & .0250 & & \\
\hline \multirow{2}{*}{$\begin{array}{l}\text { Total Years of Employment in } \\
\text { Nursing }\end{array}$} & Between Groups & 0.161 & 4 & 0.040 & \multirow{2}{*}{1.521} & \multirow{2}{*}{.2340} \\
\hline & Within Groups & .5270 & 20 & .0260 & & \\
\hline
\end{tabular}

Table (3): Association between Demographic characteristic and Studied Sample knowledge scores:

\begin{tabular}{|l|c|c|}
\hline Levels of Assessment & F & \% \\
\hline Poor: $(0.00-0.33)$ & 13 & 52.0 \\
\hline Fair(0.34-0.67) & 8 & 32.0 \\
\hline Good $(0.68-1.00)$ & 4 & 16.0 \\
\hline MS \pm SD & $0.42 \pm 0.235$ & \\
\hline
\end{tabular}

Table (4): Association between demographic Characteristics (gender, marital status, work field, the shift of work, and participations in the training course) and studied sample knowledge scores

\begin{tabular}{|c|c|c|c|c|c|}
\hline Variables & $\mathrm{N}=\mathbf{2 5}$ & Mean & t- value & df & Sig*. 2 tailed \\
\hline \multirow{2}{*}{ Gender } & Male & 0.65 & \multirow{2}{*}{5.593} & \multirow{2}{*}{23} & \multirow{2}{*}{0.000} \\
\hline & Female & 0.33 & & & \\
\hline \multirow{2}{*}{ Marital Status } & Single & 0.38 & \multirow{2}{*}{-0.482} & \multirow{2}{*}{23} & \multirow{2}{*}{0.634} \\
\hline & Married & 0.41 & & & \\
\hline \multirow{2}{*}{ Work Field } & ER & 0.43 & \multirow{2}{*}{0.703} & \multirow{2}{*}{23} & \multirow{2}{*}{0.489} \\
\hline & ICU & 0.38 & & & \\
\hline \multirow{2}{*}{ Shift of work } & Day & 0.37 & \multirow{2}{*}{-2.016} & \multirow{2}{*}{23} & \multirow{2}{*}{0.056} \\
\hline & Night & 0.57 & & & \\
\hline \multirow{2}{*}{$\begin{array}{l}\text { Participation in the } \\
\text { training course }\end{array}$} & Yes & 0.40 & \multirow{2}{*}{0.181} & \multirow{2}{*}{23} & \multirow{2}{*}{0.858} \\
\hline & No & 0.39 & & & \\
\hline
\end{tabular}

Sig. $=$ significance $<0.005, \mathrm{NS}=$ Non significance $>0.005$ 


\section{Discussion}

In the current study, the average of nurses' knowledge between 0.34 to 0.67 respectively. Despite the nurses underline fair knowledge and more than half participate in training courses, secondary school nursing graduation, but $52 \%$ of having poor knowledge regarding level of assessment. The rationale underlines just how important educational status in nurse's knowledge about head injury in critical care units. Also, the result shows a significant association between age groups and gender with their level of knowledge assessment. These results disagree with Kiewiet, where she studied professional nurses' knowledge and clinical practice regarding traumatic head injury, she found there is no significant correlation between age groups and gender and level of nurses knowledge ${ }^{[9]}$. Regarding nurses years of experience in nursing and in the current workplace, there is no significance with their knowledge. These Results share a number of similarities with Ahmed et al. findings ${ }^{[10]}$, they found the years of experience had no effect on nurses' knowledge toward trauma patients during the golden hour. In regard to the workplace, the analysis did not confirm any significant differences between nurses who work in emergency or works in the intensive care unit and their knowledge. The reason for these results, there are no specific nursing guidelines to manage patients with a traumatic head injury during golden hour in neurosurgical critical care units.

\section{Conclusion}

Despite the total nurse's knowledge was fair 0.340.67 , the majority of them were junior, graduation from secondary school nursing, and had poor knowledge toward traumatic head injury during golden hour. On the other hand, $48 \%$ of nurses not participated in continuous education lectures about traumatic head injury. Regarding these results, researchers recommend encouraging nurses who had a diploma and bachelor in nursing to work in critical care units at neurosurgical hospital and update continuous education program lectures to cover all nurses to improve their knowledge about traumatic head injury during golden hour.

Conflict of Interest: Not declared

Source of Funding: The researchers have no funding support
Ethical Clearance: This study was approved by the Institutional Ethics Committee, and The IRB was obtained from the University of Baghdad and the Ministry of Health, Directorate of Al Rusafaa Health Administration in Baghdad city.

\section{References}

1. Urden, LD, Stacy KM, Lough ME. Critical Care Nursing, Diagnosis and Management, 7: Critical Care Nursing. Elsevier Health Sciences. 2013; 7-8.

2. Hickey J. The clinical practice of neurological and neurosurgical nursing (6th ed.). Philadelphia, PA: Lippincott Williams \& Wilkins. 2009.

3. Rafiei H, Abdar M, Iranmanesh S. Knowledge about pressure ulcer prevention, classification and management: A survey of registered nurses working with trauma patients in the emergency department. International Journal of Orthopaedic and Trauma Nursing. 2014; 18(3): 135-142.

4. Marsden D. Concussion: Improving Nurses' Knowledge in the Emergency Department. Rhode Island College Digital Commons @ RIC. 2017; 21

5. Prema TP, Graicy KF. Essential Neurological and Neurosurgical Nursing. New Delhi; Jaypee brothers medical publishers. 2013; (4)

6. Jasim W. Hospital Treated Head injury in Basrah: clinical and epidemiological aspects. Thi-Qar Medical Journal. 2016; 11(1): 126-134.

7. Hashim N. Medico-Legal Study of Immediate and Delayed Deaths of Severe Head Injuries. Mustansiriya Medical Journal.2019; 7(2): 67-73.

8. Al-Jubouri M, Jaafar S. Nurses' knowledge and practice toward oral care for intubated patients. Indian Journal of Public Health Research \& Development. 2018; 9(9): 65-70

9. Kewiet J. Professional nurses' knowledge and clinical practice regarding patients with a traumatic brain injury in a tertiary hospital.2019.

10. Ahmed S, Taha N, Zatton, H. Nurses' Knowledge and Practice of Trauma Patients during Golden Hours of Care. Zagazig Nursing Journal.2017; 13(1): 244-274. 